\title{
Synthesis of Schiff Bases of 4-Amino-5- (2-Hydroxyphenyl)-4H- 1,2,4-Triazole-3-Thiol as Potent Antimicrobial Agents
}

\author{
Kamal Prasad Kapri', Som Bahadur Singar ${ }^{1}$, Santosh Khanal ${ }^{2}$, Bhushan Shakya ${ }^{1 *}$ \\ ${ }^{1}$ Department of Chemistry, Amrit Campus, Tribhuvan University, Kathmandu, Nepal \\ ${ }^{2}$ Department of Microbiology, National College, Tribhuvan University, Kathmandu, Nepal \\ *Email: bhusansakya@gmail.com
}

(Received: 23 April, 2020, Received in revised form: 7 August, 2020, Accepted: 14 August, 2020, Available online)

\section{Highlights}

- Some new aryl substituted Schiff bases of 4-amino-1,2,4-triazole were synthesized

- Synthesized compounds were characterized by spectral techniques

- Evaluated for antimicrobial activities against some pathogenic bacteria and fungi

- Antimicrobial activities were mainly due to toxicophoric part $(-\mathrm{N}=\mathrm{C}-\mathrm{N}-)$ of triazole ring

\begin{abstract}
In recent years, the emergence and rapid spread of multidrug-resistant microbes are increasingly becoming major concerns for public health because infections from such pathogens lead to higher mortality imposing huge healthcare costs. With the currently available drugs becoming ineffective due to the drug resistance developed by pathogens, the synthesis of more powerful antimicrobial agents with a broad spectrum of activity has become a crucial need for the treatment of microbial infections. Some new amino-substituted Schiff bases with triazole ring (4a-c) were prepared by cyclization of potassium 2-(2-hydroxybenzoyl) hydrazinecarbodithioate (2) with hydrazine hydrate followed by condensation with aromatic aldehydes. The newly synthesized compounds were characterized by spectral techniques like FTIR, ${ }^{1} H$-NMR, and ${ }^{13} C$-NMR. Antimicrobial screening of the synthesized compounds revealed that they possess good to moderate activities against a variety of microorganisms.
\end{abstract}

Keywords: Heterocycles, 1,2,4-Triazole, Schiff bases, Synthesis, Antimicrobial activities.

\section{Introduction}

Heterocyclic chemistry is the continuously explored and more adequately rewarding field in organic chemistry with present society and prospects (Haddad, Yousif \& Ahmed 2013). Heterocyclic compounds are of great significance to life because of their abundance in structural subunits of many natural products as well as in agrochemicals (Al-Harbi \& Gad 2018), dyes (Zhao, Qian \& Huang 2018), and many other compounds (Kumari 2018). The heterocyclic compounds with one or more hetero-atoms in ring positions have significant pharmacological activities (Chanda, Baravalia \& Baluja 2010). Among the five-membered heterocycles, the nitrogenous compounds especially 1,2,4-triazoles are abundantly found in most of the medicinal compounds. The name 'Triazole' was given to the five-membered diunsaturated ring structure composed of three nitrogen atoms and two carbon atoms at non-adjacent positions having molecular formula $\mathrm{C}_{2} \mathrm{H}_{3} \mathrm{~N}_{3}$ (Bladin 1885). Out of the isomeric pair, 1,2,4- triazole has a wide range of biological targets (Kravchenko, Panasenko \& Knysh 2018).1,2,4-Triazole nucleus and its derivatives represent one of the most biologically active class of compounds that are associated with diverse pharmacological activities such

${ }^{*}$ Corresponding author 
as antimicrobial (Barbuceanu et al., 2012), antibacterial (Hanif et al. 2012, Kapri \& Shakya 2018), antifungal (Güzeldemirci \& Küçükbasmaci 2010, Kapri \& Shakya 2018), antiviral (Holla, Akberali \& Shivananda 2001; He et al., 2014), antitubercular (Küçükgüzel, Tatar, Küçükgüzel, Rollas \& De Clerq 2008),anticancer (Holla, Poojary, Rao \& Shivananda 2002, Bekircan, Kahveci \& Kuçuk 2006; El-Sayed, Flefel \& Morsy, 2012), antioxidant (Sancak et al. 2012, Khan et al. 2010), antitumoral (Bhat, Poojary, Prasad, Naik \& Holla 2009, Al-Soud \& Al-Masoudi 2003), anti-inflammatory (Abuo-Rahma, Abdel-Aziz, Farag \& Kaoud 2014, Mousa \& Shaker 2012), anticonvulsant (Siddiqui \& Ahsan 2010, Husain, Naseer \& Sarafroz 2009), antidepressant (Demirci, Basoglu, Bozdereci \& Demirbas 2013, Kane, Dudley, Sorensen \& Miller 1988), and analgesic (Alam et al. 2012, Turan-Zitouni, Kaplancikli, Erol \& Kilic 1999) properties. Besides these, a variety of biological properties have been reported for a large number of their derivatives, such as antiprotozoal (Dürüst, Karakuş, Kaiser \& Tasdemir 2012), antimalarial (Boechat, Pinheiro, Santos-Filho \& Silva 2011), hypoglycemic, anti-urease and anti-lipase (Bekircan, Mentese, Ulker \& Kucuk 2014) etc.

Over the last few years, the synthesis of a large number of fused heterocycles from 1,2,4-triazole moiety has become an interesting task for heterocyclic chemists due to their synthetic flexibility, effective medicinal importance, safety profile and high therapeutic index. 1,2,4-triazole nucleus has been incorporated into a wide variety of therapeutically important agents that are commercially available in the markets such as Fluconazole, Itraconazole, Terconazole, Voriconazole, Ravuconazole, etc. (Richardson, Brammer, Marriott \& Troke 1985, Turan-Zitouni, Kaplancikli, Yildiz, Chevallet \& Kaya 2005). Some other commercially available and therapeutically important medicines like Alprazolam, Etizolam, Triazolam, Rizatriptan, and Furacylin, etc. also contain a 1,2,4-triazole nucleus (Street et al. 1995, Bektaş, Karaali, Şahin, Demirbaş, Karaoglu \& Demirbaş 2013).

Schiff bases, the versatile nitrogen donor molecules, are the synthetic intermediates of heterocyclic compounds usually obtained as condensation products of carbonyl compounds with primary amines. These compounds contain azomethine $(-\mathrm{CR}=\mathrm{N}-)$ group which has been demonstrated to be critical to bioactivity. Several of Schiff bases have been extensively used in biology, medicine as well as industry. They have been used as active drugs against tumor (Tadele \& Tsega 2019) and tuberculosis (Kratky et al. 2017, Sager et al. 2018), and also as insect repellents (Butler 2007) and fungicides (Shakdofa, Labib, Abdel-Hafez \& Mousa 2018).

During the past decades, the problem caused by the increasing number of multidrug-resistant microbes has reached an alarming level around the world. Therefore, the synthesis of a new class of antimicrobial agents with novel mechanisms has become an urgent need for the treatment of microbial infections. All of these remarkable observations opened horizon and new efforts have been developed for the syntheses of new Schiff bases by the reaction of 4-Amino-5-(2-hydroxyphenyl)-4H-1,2,4triazole-3-thiol with different aromatic aldehydes and were expected to exhibit a broad spectrum of antimicrobial activities.

\section{Materials and Methods}

The reagents and solvents of analytical grade viz. methyl salicylate (Fischer Scientific), hydrazine hydrate (Qualigens), carbon disulphide (Merck), ethanol (Alpha Chemika), cinnamaldehyde (Loba Chemie), vanillin (Himedia), $p$-chlorobenzaldehyde (Himedia), potassium hydroxide (Fischer Scientific), etc. were purchased from chemicals suppliers and were used without further purification.

The Melting points of the compounds were determined in the optics technology melting point apparatus. The progress of the reaction was monitored by thin layer chromatography (TLC) on silica gel coated aluminum plates and spots were observed in UV light. Infrared spectra were measured from $4000-400 \mathrm{~cm}^{-1}$ on IR Trace $100 \mathrm{FTIR}-$ Spectrometer in $\mathrm{KBr}$ pellets. ${ }^{1} \mathrm{H}-\mathrm{NMR}$ and ${ }^{13} \mathrm{C}-\mathrm{NMR}$ spectra were recorded at room temperature on Advanced III HD Fourier Transform $400 \mathrm{MHz}$ from BRUKER using TMS as an internal standard. Chemical shifts are expressed in $\delta$ ppm and signals are described as singlet (s), broad singlet (br s), doublet (d), triplet ( $\mathrm{t}$ ), and multiplet $(\mathrm{m})$. Antimicrobial activities of the compounds were evaluated according to the cup-plate assay.

\section{Experimental}

The synthetic route leading to the formation of Schiff bases is outlined in Scheme 1. 


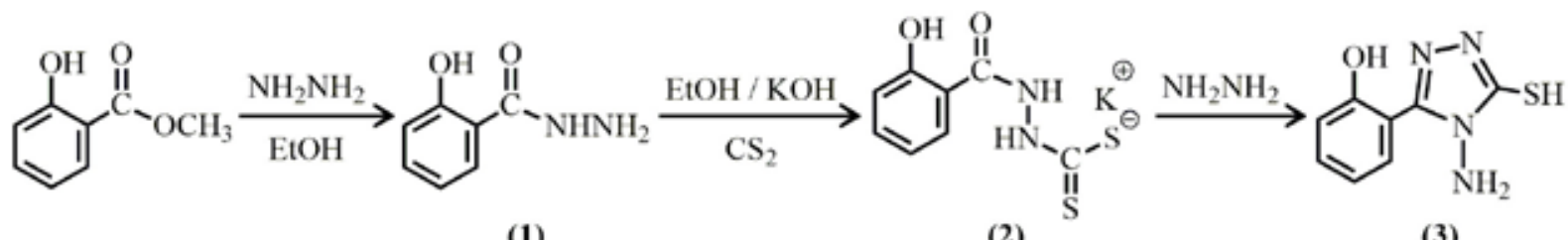

(1)<smiles>[R]C=Nn1c(S)nnc1-c1cccc(C(C)C)c1O</smiles>

(2)

$$
\begin{aligned}
4 \mathrm{a} & =\mathrm{CH}=\mathrm{CH} \mathrm{C}_{6} \mathrm{H}_{5} \\
\text { where, } \mathrm{R}=4 \mathrm{~b} & =4-\mathrm{OH} \mathrm{3-OCH} \mathrm{C}_{6} \mathrm{H}_{3} \\
4 \mathrm{c} & =4-\mathrm{Cl} \mathrm{C} \mathrm{H}_{4}
\end{aligned}
$$

(3)

(4)

Scheme 1. Synthesis of Schiff bases of triazole thiol derivatives

\section{Synthesis of 2-hydroxybenzohydrazide (1) (Furniss et al. 1991)}

The Hydrazine hydrate $(0.15 \mathrm{M})$ was added drop-wise to the solution of methyl salicylate $(0.1 \mathrm{~mol})$ in $10 \mathrm{~mL}$ of absolute ethanol with vigorous stirring and the resulting mixture was refluxed for $4 \mathrm{~h}$. The excess solvent was distilled off and then white solid obtained on cooling was collected and recrystallized from ethanol. Yield $-82 \%, \mathrm{mp} 125^{\circ} \mathrm{C}$.

\section{Synthesis of potassium 2-(2-hydroxybenzoyl) hydrazinecarbodithioate (2) (Ergenc et al. 1996)}

The ice-cold ethanolic $(10 \mathrm{~mL})$ solution of potassium hydroxide $(0.075 \mathrm{~mol})$ was added to compound (1) (0.05 mol) with constant stirring. After the dropwise addition of carbon disulphide $(0.15 \mathrm{~mol})$ the reaction mixture was agitated continuously at room temperature for $18 \mathrm{~h}$. The brownish coloured potassium salt precipitated on dilution with anhydrous diethyl ether (10 mL) was collected by filtration and dried in a desiccator. Yield $-92 \%, \mathrm{mp} 240{ }^{\circ} \mathrm{C}$.

\section{General procedure for synthesis of 4-Amino-5-(2-Hydroxyphenyl)-4H-1,2,4-Triazole-3-Thiol (3)} (Reid \& Heindel 1976)

A suspension of compound (2) $(0.04 \mathrm{~mol})$ in water $(8 \mathrm{~mL})$ and hydrazine hydrate $(0.08$ mol) was refluxed with occasional shaking till the evolution of hydrogen sulphide gas was ceased. After cooling, the reaction mixture was diluted with ice-cold water $(200 \mathrm{~mL})$. The yellowish brown solid mass separated on acidification with conc. hydrochloric acid was washed with cold water and recrystallized from ethanol. Yield: $68 \%$. mp $146{ }^{\circ} \mathrm{C}$. IR $v_{\max }$ in $\mathrm{KBr}$ (selected bands) : $\mathrm{cm}^{-1} 3377(\mathrm{O}-\mathrm{H}$ str, aromatic), $3220 \& 3096$ (N-H str), 3023 (C=CH str, aromatic), 2612 (S-H str), 1628 (C=N str), 1581-1486 (C=C str, aromatic), 1240 (O-H bend), 1015 (N-N str), 750 (C-H bend, aromatic).

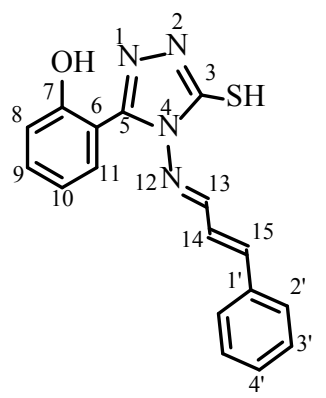

(4a)

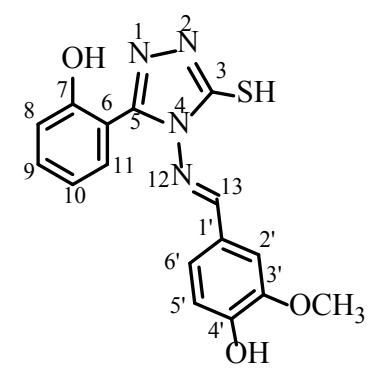

(4b)<smiles>Oc1ccccc1-c1nnc(S)n1/N=C/c1ccc(Cl)cc1</smiles>

(4c)

Fig. 1. Structures of synthesized Schiff bases

\section{Synthesis of 5-(2-Hydroxyphenyl)-4-(3-Phenylallylideneamino)-4H-1,2,4-Triazole-3-Thiol (4a)} (Mishra \& Ali 1988)

A hot ethanolic solution of compound (3) (0.01 mol) was added dropwise to a mixture of hot ethanolic solution of cinnamaldehyde $(0.01 \mathrm{~mol})$ and $4-5$ drops of concentrated sulphuric acid, with constant agitation. The resulting mixture was 
refluxed for $3 \mathrm{~h}$ and the brownish yellow solid precipitated was collected, washed with cold ethanol and recrystallized with hot ethanol. Yield: $66 \%$. mp 197-200 ${ }^{\circ} \mathrm{C}$. IR $v_{\max }$ in $\mathrm{KBr}$ (selected bands): $\mathrm{cm}^{-1} 3085$ (O-H str, aromatic), 2948 (C=CH str, aromatic), 2591 (S-H str), 1602 (C=N str), 1551-1488 (C=C str, aromatic), 1250 (O-H bend, aromatic), 1052 (N-N str), 750 (C-H bend, aromatic). ${ }^{1} \mathrm{H}$ NMR (400 MHz, DMSO-d 6 ) : $\delta$ ppm $14.07(1 \mathrm{H}$, br s, S프), $10.07(1 \mathrm{H}, \mathrm{br} \mathrm{s}, \mathrm{OH}), 9.35(1 \mathrm{H}, \mathrm{d}, \mathrm{J}=9.5 \mathrm{~Hz}, \mathrm{H}-13)$, 7.78-7.65 (2H, m, H-2'), 7.53-7.29 (6H, m, H-9, H-11, H-15, H-3', H-4'), 7.13 (1H, dd, J = 15.9 Hz, J = 9.5 Hz, H-14), 7.02-6.87 (2H, m, H-8, H-10). ${ }^{13} \mathrm{C}$ NMR (100 MHz, DMSO-d 6 ) : $\delta$ ppm 167.8 (C-3), 161.6 (C-13), $156.2(\mathrm{C}-7), 148.2$ (C-5), 146.5 (C-1'), 134.9 (C-15), 132.3 (C-11), 131.1 (C-9), 130.2 (C-3') , 128.9 (C-2') , 128.0 (C-4'), 123.5 (C-10), 118.9 (C-14), 115.6 (C-6), 113.0 (C-8).

\section{Synthesis of 4-(4-Hydroxy-3-Methoxybenzylideneamino)-5-(2-Hydroxyphenyl)-4H-1,2,4-Tri- azole-3-Thiol (4b)}

To a mixture of hot ethanolic solution of Vanillin $(0.01 \mathrm{~mol})$ and 4-5 drops of concentrated sulphuric acid, a hot ethanolic solution of compound (3) $(0.01 \mathrm{~mol})$ was added in small fractions with vigorous shaking. The content was refluxed for $3 \mathrm{~h}$ and the off-white solid thus precipitated was collected, washed with cold ethanol and recrystallized with hot ethanol. Yield: $60 \%$. mp 202-205 ${ }^{\circ} \mathrm{C}$. IR $v_{\max }$ in $\mathrm{KBr}$ (selected bands): $\mathrm{cm}^{-1} 3297$ (O-H str, aromatic), 2605 (S-H str), 1578 (C=N str), 1534-1466 (C=C str, aromatic), $\left.1275\left({\mathrm{O}-\mathrm{CH}_{3}}_{3} \text {, str), } 1252 \text { (O-H bend), } 1136 \text { (N-N str), } 730 \text { (C-H bend, aromatic). }{ }^{1} \mathrm{H} \text { NMR (400 MHz, DMSO-d }\right)_{6}\right)$

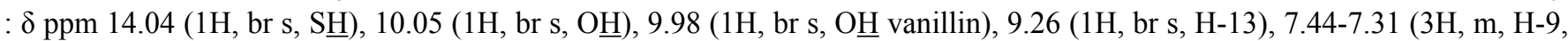
H-11, H-2'), 7.30-7.25 (1H, m, H-6'), 6.99-6.86 (3H, m, H-8, H-10, H-5'), 3.77 (3H, br s, $\left.\mathrm{C}_{3}\right) .{ }^{13} \mathrm{C}$ NMR (100 MHz, DMSO-d $)$ : $\delta$ ppm 166.6 (C-3), 161.9 (C-13), 156.2 (C-7), 151.3 (C-5), 148.2 (C-4'), 148.0 (C-3'), 132.3 (C-11), 131.2 (C-9), 124.1 (C-1'), 123.4 (C-6'), 118.9 (C-10), 116.0 (C-6), 115.7 (C-8), 113.0 (C-5'), 110.9 (C-2'), $55.6\left(\underline{\mathrm{CH}}_{3}\right)$.

\section{Synthesis of 4-(4-Chlorobenzylideneamino)-5-(2-Hydroxyphenyl)-4H-1,2,4-Triazole-3-Thiol (4c)}

To a hot ethanolic solution $(15 \mathrm{~mL})$ of compound (3) $(0.01 \mathrm{~mol})$, a mixture of hot ethanolic solution $(15 \mathrm{~mL})$ of $p$-chlorobenzaldehyde $(0.01 \mathrm{~mol})$ and $4-5$ drops of conc. sulphuric acid, was added fractionally with constant stirring. The resulting mixture was heated for $3 \mathrm{~h}$ under reflux condition and the brown solid obtained was filtered, washed with cold ethanol and recrystallized with hot ethanol. Yield: $62 \%$. mp $187-190{ }^{\circ} \mathrm{C}$. IR $v_{\max }$ in $\mathrm{KBr}$ (selected bands): $\mathrm{cm}^{-1} 3100$ (O-H str, aromatic), 2940 (C=CH str, aromatic), 2586 ( $\mathrm{S}-\mathrm{H}$ str), 1583 (C=N str), 1545 - 1496 (C=C str, aromatic), 1248 (O-H bend, aromatic), 1098 (N-N str), 747 (C-H bend, aromatic), 620 (C-Cl str). ${ }^{1} \mathrm{H}$ NMR (400 MHz, DMSO-d $\left.{ }_{6}\right): \delta$ ppm $14.15(1 \mathrm{H}, \mathrm{br} \mathrm{s}, \mathrm{S} \underline{\mathrm{H}}), 10.07(1 \mathrm{H}, \mathrm{s}$, $\mathrm{OH}), 9.70$ (1H, s, H-13), 7.80 (2H, d, J=8.1 Hz, H-2'), 7.58 (2H, d, J=8.1 Hz'), 7.47-7.22 (2H, m, H-9, H-11), 7.16-6.84 (2H, m, H-8, H-10). ${ }^{13} \mathrm{C}$ NMR (100 MHz, DMSO-d 6 ) : $\delta$ ppm 164.0 (C-3), 161.8 (C-13), 156.2 (C-7), 148.4 (C-5), 137.3 (C-4'), 132.4 (C-11), 131.1 (C-2'), 131.0 (C-1'), 130.2 (C-9), 129.3 (C-3'), 118.9 (C-10), 113.0 (C-6), 112.8 (C-8).

\section{Antimicrobial screening}

The antimicrobial activities of triazole thiol derivatives (4a-c) in two different concentrations $(1 \%$ and $5 \%)$ were evaluated against various microorganisms, representing Gram-positive bacteria (Staphylococcus aureus), Gram-negative bacteria (Escherichia coli and Klebsiella pneumoniae) and fungus (Candida albicans), according to the cup-plate assay. The overnight culture of bacterial and fungal species from nutrient agar and Sabouraud dextrose agar respectively were adjusted to $0.5 \mathrm{McFarland}$ standards and was spread on the surfaces of Muller-Hinton agar plates using a sterile cotton swab to prepare microbial lawns. The suitably spaced apart wells of $6 \mathrm{~mm}$ diameter were made on each agar plate and the labeled wells were loaded with $50 \mu \mathrm{L}$ of each triazole solution. Ofloxacin $(32 \mu \mathrm{g} / \mathrm{mL})$ and Fluconazole $(40 \mu \mathrm{g} / \mathrm{mL})$ were used as reference antimicrobials and DMSO was used as a negative control. The Petri dishes were kept 30 minutes for diffusion and incubated at $37^{\circ} \mathrm{C}$ for $24 \mathrm{~h}$. After incubation, the diameters of the inhibition zones were measured in $\mathrm{mm}$ and the results of antimicrobial activities were interpreted.

\section{Results and Discussion}

\section{Chemistry}

Schiff bases of 4-Amino-5-(2-hydroxyphenyl)-4H-1,2,4-triazole-3-thiol bases (4a-c) were synthesized from methyl salicylate. Methyl salicylate was converted into corresponding acid hydrazide (1) by treating with hydrazine monohydrate. The acid hydrazide (1) was treated with carbon disulphide in presence of ethanolic potassium hydroxide to obtain potassium 
dithiocarbazinate (2). The intermediate (2) was refluxed with hydrazine monohydrate and the resulting triazole thiol (3) was condensed with desired aldehyde to get the Schiff base (4). The Schiff bases (4a-c) were obtained in good yield. They were stable in air at room temperature, slightly soluble in $\mathrm{CHCl}_{3}$, and readily soluble in polar solvents like MeOH and DMSO. The structures of the synthesized compounds were confirmed by IR, ${ }^{1} \mathrm{H}-\mathrm{NMR}$ and ${ }^{13} \mathrm{C}-\mathrm{NMR}$ spectroscopy.

\section{Antimicrobial evaluation}

The diameters of inhibition zones (Table 1) indicate that all three compounds (4a-c) exhibited various degrees of antimicrobial activity against the tested microbial species. Among the tested microorganisms, the inhibition of bacterial growth was more pronounced in Gram-positive bacteria $S$. aureus. A significant inhibitory effect was observed for all compounds against $K$. pneumoniae. Conversely, the compounds were found to be relatively less effective against $E$. coli as compared to the other two bacterial species. Moreover, the compounds were able to give a moderate inhibitory activity against a fungal species of Candida albicans where the compound $\mathbf{4 c}$ displayed least activity against it.

The compounds $\mathbf{4 a}$ and $\mathbf{4 b}$ containing electron donating groups 3-phenylallyl and 4-Hydroxy-3-methoxybenzyl groups respectively were found to exhibit more potent activity compared to compound $\mathbf{4 c}$ containing electron withdrawing 4-Chlorobenzyl group. This indicate that the electron density on N-4 position of 1,2,4-triazole nucleus can affect the antibacterial and antifungal activities. The slightly enhanced antibacterial and antifungal activity of $\mathbf{4 a}$ and $\mathbf{4 b}$ may be due to the electron donating ability of the substituents on $\mathrm{N}-4$ position.

Table 1. Inhibition zones showing antimicrobial activities of Schiff bases and the references antibiotic

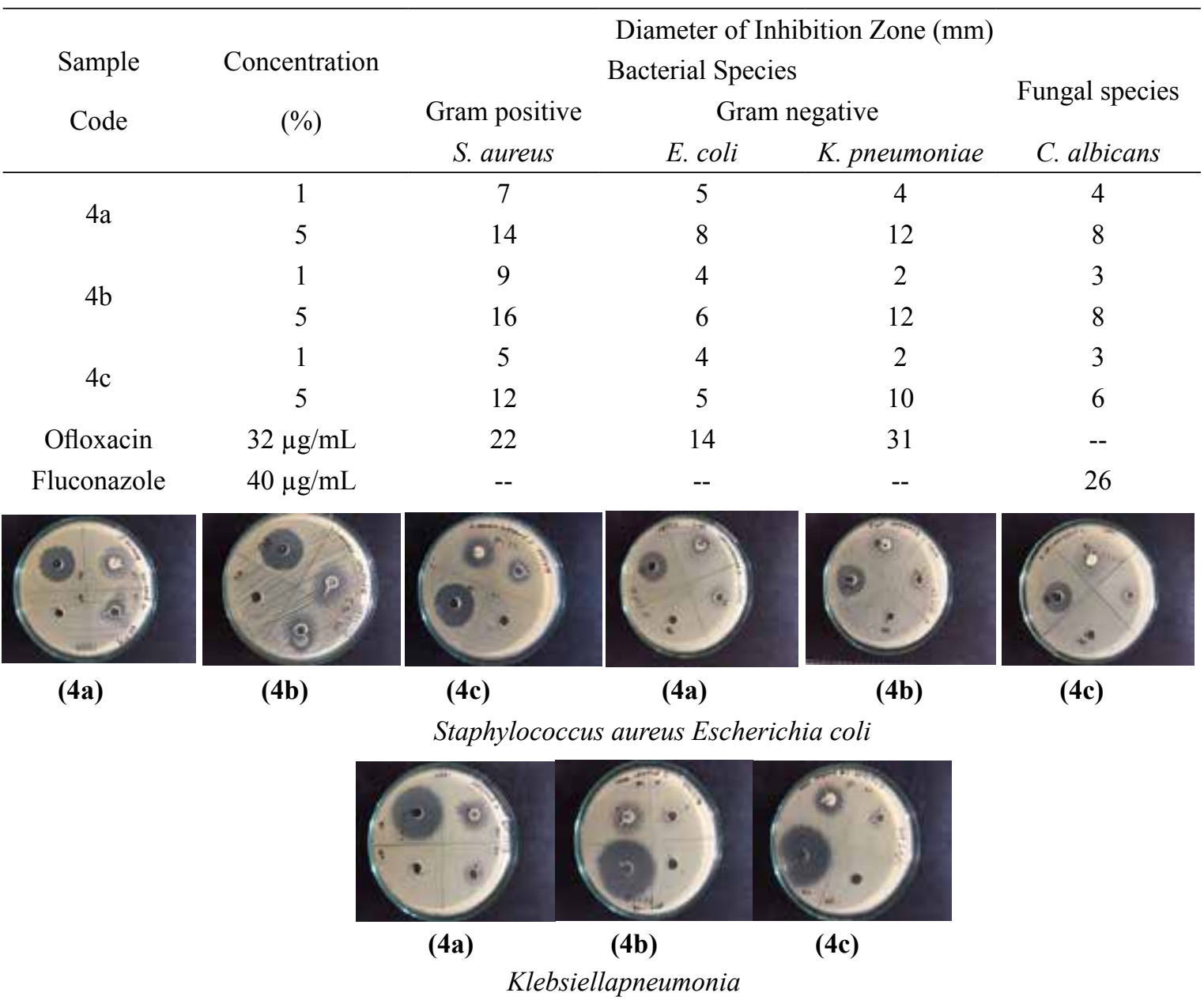

Fig. 2. Antibacterial activity of synthesized compounds 


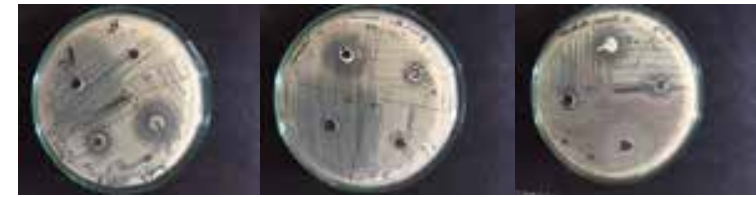

(4a) (4c)

Fig. 3. Antifungal activity of synthesized compounds on Candida albicans

\section{Conclusions}

The present study highlighted the successful synthesis of three new Schiff bases of 1,2,4-triazole derivatives viz. 5-(2-Hydroxyphenyl)-4-(3-phenylallylideneamino)-4H-1,2,4-triazole-3-thiol, 4a; 4-(4-Hydroxy-3-methoxybenzylideneamino)5-(2-hydroxyphenyl)-4H-1,2,4-triazole-3-thiol, $\quad \mathbf{4 b}$ and 4-(4-Chlorobenzylideneamino)-5-(2-hydroxyphenyl)-4H-1,2,4triazole-3-thiol, $\mathbf{4 c}$ starting from methyl salicylate via 4 steps. The molecular structures of newly synthesized compounds were characterized by analytical and spectral techniques. All the Schiff bases exhibited good to moderate antimicrobial activities against the tested microbial species. The activity of all compounds against Gram-positive bacteria were found to be more as compared to Gram-negative bacteria probably due to highly polar substituents in the synthesized compounds. Compound $\mathbf{4 c}$ with electron withdrawing 4-Cl- $\mathrm{C}_{6} \mathrm{H}_{4}$ substituent exhibited comparatively lesser antibacterial and antifungal activities. Though the change in electron density on triazole ring due to difference in substituents at N-4 position affect the antimicrobial activity, the little difference in the activity of the synthesized compounds suggests that the antimicrobial activities were mainly due to the $-\mathrm{N}=\mathrm{C}-\mathrm{N}-$ toxicophoric part of the triazole ring.

\section{Acknowledgments}

We are very grateful to the Central Department of Chemistry (Tribhuvan University, Kirtipur) for FT-IR spectra, Dr. Deval Prasad Bhattarai and Dr. Ek Raj Baral (Chonbuk National University, South Korea) for recording NMR spectra, and National College (Khusibu, Nayabazaar) for antimicrobial screening.

\section{References}

Abuo-Rahma, G.E., Abdel-Aziz, M., Farag, N.A., and Kaoud, T.S. 2014. Novel 1-[4-(aminosulfonyl)phenyl]-1H-1,2,4-triazole derivatives with remarkable selective COX-2 inhibition: Design, synthesis, molecular docking, anti-inflammatory and ulcerogenicity studies. European Journal of Medicinal Chemistry,83(18): 398-408.

Al-Harbi, E.A., and Gad, W.A. 2018. Nitrogen-containing heterocycles in agrochemicals. Agricultural Research and Technology, 16(2):555986. DOI: 10.19080/ARTOAJ.2018.16.555986.

Al-Soud, Y.A.,and Al-Masoudi, N. 2003. Synthesis and properties of new substituted 1,2,4-triazoles: potential antitumor agents. Bioorganic Medicinal Chemistry, 11(8): 1701-1708.

Alam, M.M., Nazreen, S., Haider, S., Shafi, S., Yar, M.S., Hamid, H., and Alam, M.S. 2012. Synthesis of some new S-alkylated 1,2,4-triazoles, their Mannich bases and their biological activities. Archiv Der Pharmazie, 345(3): 203-214.

Barbuceanu, S.F., Saramet, G., Almajan, G.L., Draghici, C., Barbuceanu, F.and Bancescu, G. 2012. New heterocyclic compounds from 1,2,4-triazole and 1,3,4-thiadiazole class bearing diphenylsulfone moieties. Synthesis, characterization and antimicrobial activity evaluation. European Journal of Medicinal Chemistry, 49:417-423.

Bekircan, O., Kahveci, B. and Kuçuk, M. 2006. Synthesis and anticancer evaluation of some new unsymmetrical 3,5-diaryl-4H1,2,4-triazole derivatives. Turkish Journal of Chemistry, 30(1): 29-40.

Bekircan, O., Mentese, E., Ulker, S., and Kucuk, C. 2014. Synthesis of some new 1,2,4-triazole derivatives starting from 3-(4-chlorophenyl)-5-(4-methoxybenzyl)-4H-1,2,4-triazole with anti-lipase and anti-urease activities. Archiv Der Pharmazie 347(6): 387-397.

Bekircan, O., Ulker, S., and Mentese, E. 2014. Synthesis of some novel heterocyclic compounds derived from 2-[3-(4-chlorophenyl)5-(4-methoxybenzyl)-4H-1,2,4-triazol-4yl]acetohydrazideand investigation of their lipase and $\alpha$-glucosidase inhibition. 
Journal of Enzyme Inhibition and Medicinal Chemistry, 30(6): 1002-1009.

Bektaş, H., Karaali, N., Şahin, D., Demirbaş, A., Karaoglu, Ş.A., andDemirbaş, N. 2013. Synthesis and antimicrobial activities of some new 1,2,4-triazole derivatives. Molecules, 15(4): 2427-2438.

Bhat, K.S., Poojary, B., Prasad, D.J., Naik, P., and Holla, B.S. 2009. Synthesis and antitumor activity studies of some new fused 1,2,4-triazole derivatives carrying 2,4-dichloro-5-fluorophenyl moiety. European Journal of Medicinal Chemistry, 44(12):5066-5070.

Bladin, J.A. 1885. Ueber von dicyanphenylhydrazin abgeleitete verbindungen. Berichte der Deutschen Chemischen Gesellschaft, 18: $1544-1551$.

Boechat, N., Pinheiro, L.C., Santos-Filho, O.A., and Silva, I.C. 2011. Design and synthesis of new $N$-(5-trifluoromethyl)-1H1,2,4-triazol-3-yl benzenesulfonamides as possible antimalarial prototypes. Molecules, 16(9): 8083-8097.

Butler, J.F. 2007. Use of olfactometers for determining attractants and repellents. In Debboun, M., Frances, S.P., and Strickman, D. (Eds.), Insect repellents: principles, methods and uses (pp 161-194). Boca Raton, FL: CRC, Press.

Chanda, S., Baravalia, Y., and Baluja, S. 2010. Synthesis and antibacterial activity of some new triazole derivatives. Archives of Applied Science Research, 2(3): 117-126.

Demirci, S., Basoglu, S., Bozdereci, A., and Demirbas, N. 2013. Preparation and antimicrobial activity evaluation of some new bi- and triheterocyclic azoles. Medicinal Chemistry Research, 22(10): 4930-4945.

Dürüst, Y., Karakuş, H., Kaiser, M., and Tasdemir, D. 2012. Synthesis and anti-protozoal activity of novel dihydropyrrolo[3,4- $d]$ [1,2,3] triazoles. European Journal of Medicinal Chemistry, 48: 296-304.

El-Sayed, W.A., Flefel, E.M., and Morsy, E.M. 2012. Anticancer and antimicrobial activities of some synthesized pyrazole and triazole derivatives. Der Pharma Chemica, 4(1): 23-32.

Ergenc, N., Ulusoy, N., Capan, G., Sanis, G.O. and Kiraz, M. 1996. Synthesis and antimicrobial properties of new 4-(alkylidene/ arylidene)-amino-5-(2-furanyl)-2,4-dihydro-3H-1,2,4-triazole-3-thiones and 6-aryl-3-(2-furanyl)-7H-1,2,4-triazole[3,4-b] $[1,3,4]$ thiadiazines, Archiv der Pharmazie, 329(8-9), 427-430.

Furniss, B.S., Hannaford, A.J., Smith, P.W.G. and Tatchell, A. R. 1991. Vogel's Text Book of Practical Organic Chemistry, $5^{\text {th }}$ Ed. Longman Scientific and Technical, copublished in the United States with John Wiley and Sons Inc.: New York, USA, pp. 1269.

Güzeldemirci, N.U., and Küçükbasmaci, Ö. 2010. Synthesis and antimicrobial activity evaluation of new 1,2,4-triazoles and 1,3,4-thiadiazoles bearing imidazo[2,1-b]thiazole moiety. European Journal of Medicinal Chemistry, 45(1): 63-68.

Haddad, R., Yousif, E., and Ahmed, A. 2013. Synthesis and characterization of transition metal complexes of 4-Amino-5-pyridyl4H-1,2,4-triazole-3-thiol. SpringerPlus, 2(1): 1-6.

Hanif, M., Saleem, M., Hussain, M.T., Rama, N.H., Zaib, S., Aslam, M.A., Jones, P.G., and Iqbal, J. 2012. Synthesis, urease inhibition, antioxidant and antibacterial studies of some 4-amino-5-aryl-3H-1,2,4-triazole-3-thiones and their 3,6-disubstituted 1,2,4-[3,4-b]1,3,4-thiadiazole derivatives. Journal of the Brazilian Chemical Society, 23(5): 854-860.

He, Y., Dong, C., Zhao, J., Ma, L., Li, H., and Aisa, H.A. 2014. 1,2,3-Triazole-containing derivatives of rupestonic acid: Clickchemical synthesis and antiviral activities against influenza viruses. European Journal of Medicinal Chemistry, 76(9): 245-255.

Holla, B.S., Akberali, P.M., and Shivananda, M.K. 2001. Studies on nitrophenylfuran derivatives: part XII. Synthesis, characterization, antibacterial and antiviral activities of some nitrophenylfurfurylidene-1,2,4-triazolo-[3,4-b]-1,3,4thiadiazines. Il Farmaco, 56(12): 919-927.

Holla, B.S., Poojary, K.N., Rao, B.S., and Shivananda, M.K. 2002. New bis-aminomercaptotriazoles and bis-triazolothiadiazoles as possible anticancer agents. European Journal of Medicinal Chemistry, 37(6): 511-517.

Husain, A., Naseer, M.A. and Sarafroz, M. 2009. Synthesis and anticonvulsant activity of some novel fused heterocyclic 1,2,4-triazolo-[3,4-b]-1,3,4-thiadiazole derivatives. Acta Poloniae Pharmaceutica, 66(2): 135-140.

Kapri, K.P., and Shakya, B. 2018. Synthesis, characterization and antimicrobial evaluation of Schiff bases of 4-amino-5-(4-tertbutylphenyl)-4H-1,2,4-triazole-3-thiol. Journal of Nepal Chemical Society, 39: 1-9.

Kane, J.M., Dudley, M.W., Sorensen, S.M., and Miller, F.P. 1988. 2,4-Dihydro-3H-1,2,4-triazole-3-thiones as potential antidepressant agents. Journal of Medicinal Chemistry, 31(6): 1253-1258. 
Khan, I., Ali, S., Hameed, S., Rama, N.H., Hussain, M.T., Wadood, A. Uddin, R. Haq, Z., Khan, A., Ali, S., and Choudhary, M.I. 2010. Synthesis, antioxidant activities and urease inhibition of some new 1,2,4-triazole and 1,3,4-thiadiazole derivatives. European Journal of Medicinal Chemistry, 45(11): 5200-5207.

Krátký, M., Dzurková, M., Janoušek, J., Kone`cná, K., Trejtnar, F., Stola ríková, J., and Vinšová, J. 2017. Sulfadiazine salicylaldehyde-based Schiff bases: Synthesis, antimicrobial activity and cytotoxicity. Molecules, 22: 1573; doi:10.3390/ molecules22091573.

Kravchenko, T.V., Panasenko, O.I., and Knysh, E.G. 2018. Biological activity of the derivatives of 1,2,4-triazole. Farmatsevtychnyi Zhurnal, 5: 25-30.

Küçükgüzel, I., Tatar, E., Küçükgüzel, Ş.G., Rollas, S.,and De Clerq, E. 2008. Synthesis of some novel thiourea derivatives obtained from 5-[(4-aminophenoxy)methyl]-4-alkyl/aryl-2,4-dihydro-3H-1,2,4-triazole-3-thiones and evaluation as antiviral/anti-HIV and anti-tuberculosis agents. European Journal of Medicinal Chemistry, 43(2): 381-392.

Kumari, J. 2018. Application of heterocyclic compounds in everyday life. Journal of Modern Chemistry and Chemical Technology, 9(1): 1-7.

Mishra, B. and Ali, R. 1988. A novel synthesis of $s$-triazolo[3,4-b][1,3,4] thiadiazole derivatives, Indian Journal of Chemistry, 27B, 576-577.

Mousa, M.N., and Shaker. A.N. 2012. Evaluation of the anti-inflammatory activity and ulcerogenic liability of 5-(3-chloro-1benzothien-2-yl)-4-phenyl-4H-1,2,4-triazole-3-thiol. Basrah Journal of Veterinary Research, 11(1): $122-127$.

Reid, J.R. and Heindel, N.D. 1976. Improved synthesis of 5-substituted-4-amino-3-mercapto-(4H)-1,2,4-triazoles, Journal of Heterocyclic Chemistry, 13, 925-926.

Richardson, K., Brammer, K.W., Marriott, M.S., and Troke, P.F. 1985. Activity of UK-49, 858, a bis-triazole derivative, against experimental infections with Candida albicans and Trichophyton mentagrophytes. Antimicrobial Agents and Chemotherapy, 27(5): 832-835.

Sager A.A., Abood, Z.S., El-Amary, W.M., Bensaber, S.M., Al-Sadawe, I.A., Ermeli, N.B., Mohamed S.B., Al-Forgany, M., Mrema, I.A., Erhuma, M., Hermann, A. and Gbaj A.M. 2018. Design, synthesis and biological evaluation of some triazole Schiff's base derivatives as potential antitubercular agents. The Open Medicinal Chemistry Journal, 12: 48-59.

Sancak, K., Ünver, Y., Ünlüer, D., Düğdü, E., Kör, G., Çelik, F., and Birinci, E. 2012. Synthesis, characterization, and antioxidant activities of new trisubstituted triazoles. Turkish Journal of Chemistry, 36(3): 457-466.

Shakdofa, M.M., Labib, A.A., Abdel-Hafez, N.A. and Mousa, H.A. 2018. Synthesis and characterization of $\mathrm{VO}^{2+}, \mathrm{Co}^{2+}, \mathrm{Ni}^{2+}$, $\mathrm{Cu}^{2+}$ and $\mathrm{Zn}^{2+}$ complexes of a Schiff base ligand derived from ethyl 2-amino-6-ethyl-4,5,6,7-tetrahydrothieno[2,3-c] pyridine-3-carboxylate and their investigation as fungicide agents. Applied Organometallic Chemistry, 31(12); doi. org/10.1002/aoc.4581.

Siddiqui, N., and Ahsan, W. 2010. Triazole incorporated thiazoles as a new class of anticonvulsants: Design, synthesis and in vivo screening. European Journal of Medicinal Chemistry, 45(4): 1536-1543.

Singhal, N., Sharma, P.K., Dudhe, R., and Kumar, N. 2011. Recent advancement of triazole derivatives and their biological significance. Journal of Chemistry and Pharmaceutical Research,3(2): 126-133.

Street, L.J., Baker, R., Davey, W.B., Guiblin, A.R., Jelley, R.A., Reeve, A.J., Routledge, H., Sternfeld, F., Watt, A.P., and Matassa, V.G. 1995. Synthesis and serotonergic activity of $N, N$-dimethyl-2-[5-(1,2,4-triazol-1-ylmethy1)-1H-indol-3-yl]ethylamine and analogues: Potent agonists for 5-HT1D receptors. Journal of Medicinal Chemistry, 38(10): 1799-1810.

Tadele, K.T. and Tsega, T.W. 2019. Schiff bases and their metal complexes as potential anticancer candidates: A review of recent works. Anti-Cancer Agents in Medicinal Chemistry, doi: 10.2174/1871520619666190227171716).

Turan-Zitouni, G., Kaplancikli, Z., Erol, K., and Kilic, F.S. 1999. Synthesis and analgesic activity of some triazoles and triazolothiadiazines. Il Farmaco, 54(4): 218-223.

Turan-Zitouni, G., Kaplancikli, Z., Yildiz, M.T., Chevallet, P., and Kaya, D. 2005. Synthesis and antimicrobial activity of 4-phenyl/cyclohexyl-5-(1-phenoxyethyl)-3-[N-(2-thiazolyl)acetamido]thio-4H-1,2,4-triazolederivatives. European Journal of Medicinal Chemistry, 40(6): 607-613.

Zhao, X.L., Qian, H.F. and Huang, W. 2018. Construction of benzothiazle/pyridone based bi-heterocyclic dyes and their Ni ${ }^{\mathrm{II}}$ and $\mathrm{Cu}^{\mathrm{II}}$ complexes. Dyes and Pigments, 149: 796-803. 